Check for updates

Cite this: RSC Adv., 2018, 8, 19494

Received 10th May 2018

Accepted 21st May 2018

DOI: $10.1039 / \mathrm{c} 8 \mathrm{ra03989e}$

rsc.li/rsc-advances

\section{Diasteroselective multi-component assemblies from dynamic covalent imine condensation and metal-coordination chemistry: mechanism and narcissistic stereochemistry self-sorting $\dagger$}

\author{
Elena Badetti, (D) a Nadia Alessandra Carmo dos Santos, (D) a \\ Francesca A. Scaramuzzo, (D) Carlo Bravin, (D) ${ }^{a}$ Klaus Wurst, (D) ${ }^{b}$ Giulia Licini (iD) ${ }^{a}$ \\ and Cristiano Zonta (D)*a
}

\begin{abstract}
Self-assembly of a modified tris(2-pyridylmethyl)amine TPMA ligand, zinc(॥) or cobalt(॥) ions, and amino acids have been used effectively as stereo dynamic optical probes for the determination of the enantiomeric excess of free amino acids either using Electronic or Vibrational Circular Dichroism (CD and VCD). Herein, we report the mechanistic and stereochemical study of the self-assembly process which reveals a complex equilibrium in solution where even small variations in the experimental conditions can profoundly affect the final products of the reaction. In particular, variation on the metal stoichiometry switch give rises to an entirely enantio narcissistic self-assembly of the structure.
\end{abstract}

\section{Introduction}

One of the leading strategies for the development of complex functional nano-architectures is the use of dynamic covalent chemistry (DCC) in which imine condensation and metalcoordination work simultaneously. ${ }^{1}$ These two "orthogonal" thermodynamically driven association processes have successfully and effectively yield a large variety of compounds, ranging from simple complexes to topological structures. ${ }^{2}$ This approach has been effectively used for the development of methods that allow the determination of optical purity. ${ }^{3}$ In particular, the focus was driven towards the development of stereodynamic optical probes ${ }^{4}$ for the rapid determination of the enantiomeric excess (e.e.) of chiral compounds. In general, these systems are characterized by the presence of at least one labile stereogenic element which, after the addition of a chiral analyte, moves toward the formation of one preferential diastereoisomer. Most of the times, this information is translated into a signal by the use of optical techniques such as circular dichroism (CD). ${ }^{5}$

Recently, we have been working with tris(2-pyridylmethyl) amine (TPMA) metal complexes both in catalysis ${ }^{6}$ and supramolecular chemistry. ${ }^{7}$ Within these studies, we reported a series

${ }^{a}$ Department of Chemical Sciences, University of Padova, Via Marzolo 1, 35131 Padova (PD), Italy.E-mail: cristiano.zonta@unipd.it

${ }^{b}$ Institute of General, Inorganic and Theoretical Chemistry, University of Innsbruck, Innrain 80/82, 6020 Innsbruck, Austria

$\dagger$ Electronic supplementary information (ESI) available. CCDC 1583270. For ESI and crystallographic data in CIF or other electronic format see DOI: 10.1039/c8ra03989e of novel molecular architectures that can be used for the determination of the e.e. of free amino acids (Fig. 1). ${ }^{7 a, 7 b, 8}$ More in detail, the mix of a modified TPMA zinc complex with one equivalent of the desired amino acid resulted in the almost exclusive formation of the dinuclear architecture 1-aaa. The mixture was used without further purification for CD measurements. The obtained curves directly correlate with the e.e. and specular curves were obtained switching the configuration of the amino acids. Beside the capability of the system to be effective with all natural amino acids, it displayed absorptions which were characteristic of the amino acidic side chain, differentiating clearly the aliphatic or aromatic nature of the backbone. TD-DFT studies have shown that CD signals arise by
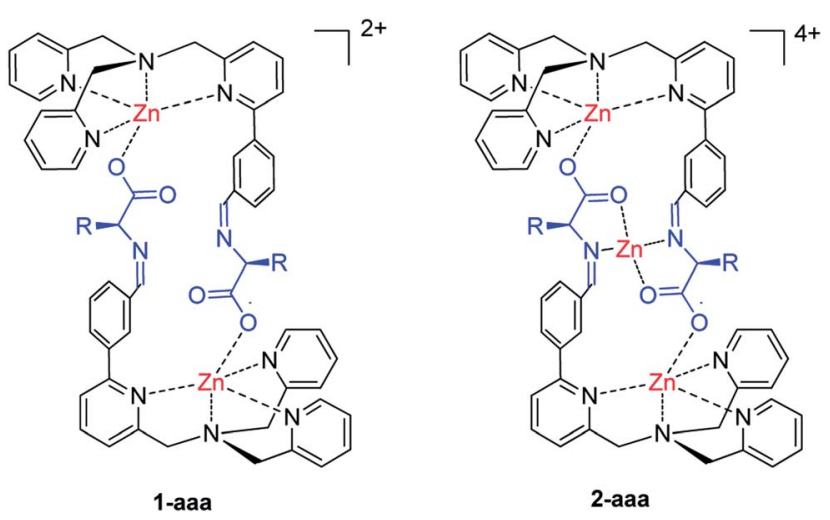

Fig. 1 Dinuclear 1-aaa and trinuclear 2-aaa self-assembled structures used as probes for the determination of e.e. of amino acids. The counteranions are perchlorate. 
the helical arrangement of the ligand around the metal, and by the exciton coupling of the atropoisomeric biarylic systems. In addition, from studies on the 1-aaa complex stability we could identify the structure 2-aaa, in which an extra-metal get coordinated by the cleft formed between the two amino acids. ${ }^{7 b}$

These initial findings have driven our interest towards the investigation of the whole process taking place in solution, with the two-fold intention of better understanding the self-assembly mechanism and elucidating how the stereochemistry dictates products distribution. The elucidation of the equilibrium present in solution, when imine DCC is used in the presence of metals, highlights that increasing system complexity leads to sharp changes in products distribution and stereochemistry from small variations of the chemical parameters.

\section{Results and discussion}

In order to shed light on the mechanism behind the formation of bi- and tri-nuclear dimers, a step-by-step analysis has been performed evaluating how different thermodynamic, kinetic and stereochemical parameters are affecting the assembly formation and, consequently, the dichroic signal. Starting from complex 3, the delicate interplay of all the components present in the reaction mixture was revealed.

\section{Intermediates in the self-assembly process}

Acetal 4 and 5-L-Phe. Zinc(II) complex $3,^{7 a}$ bearing a formyl group in meta position to the pyridine ring, is highly soluble in methanol and allows to observe by ${ }^{1} \mathrm{H}-\mathrm{NMR}$, at room temperature, the slow formation of the corresponding acetal 4 (Scheme 1 and Fig. 2b).

The complete conversion of 3 to 4 requires two days at room temperature but only 4 hours at $60^{\circ} \mathrm{C}$. The reaction can be easily monitored by ${ }^{1} \mathrm{H}-\mathrm{NMR}$, following the disappearance of the aldehydic signal of 3 at $10.02 \mathrm{ppm}$ and the appearance of the signal of acetal 4 at $5.37 \mathrm{ppm}$ (Fig. 2b). Acetal formation is also confirmed by 2D-NMR HMQC experiment which correlates acetal proton signal with the characteristic ${ }^{13} \mathrm{C}$ signal at $105 \mathrm{ppm}$.

Upon adding the amino acid $\mathbf{L}-P h e$ to acetal $\mathbf{4}$, the formation of a new species is instantaneously observed (Fig. 2c). It is

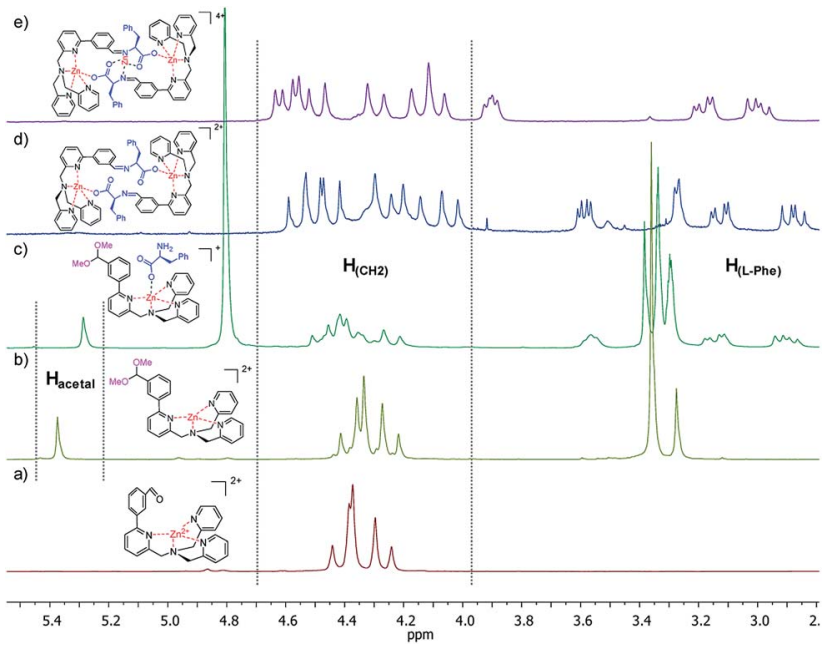

Fig. 2 Comparison of the ${ }^{1} \mathrm{H}-\mathrm{NMR}$ signals for the compounds 1, 4, 5-L-Phe, 1-L-Phe and 2-L-Phe in $\mathrm{D}_{3}$-acetonitrile. In this region acetal (5.4 to $5.2 \mathrm{ppm}$ ), $\mathrm{CH}_{2}$ pycolil (4.6 to $3.9 \mathrm{ppm}$ ) and amino acid (3.8 to 2.7 ppm) proton signals are present. The counteranions are perchlorate.

possible to ascribe this structure to the adduct 5-L-Phe in which the amino acidic carboxylate binds to the zinc centre. This compound is highly stable in solution as variation of ${ }^{1} \mathrm{H}$ NMR signals are not observed: (i) increasing the temperature, (ii) leaving the compound in solution for weeks, (iii) adding extra equivalents of amino acid or (iv) extra zinc salt to the sample. In these cases, the intensity of the acetal signal remains constant. Moreover, ${ }^{1} \mathrm{H}$ NMR highlights a broadness of the picolyl $\mathrm{CH}_{2}$ signals (4.2-4.5 ppm) slightly different from the parent compounds 3 and 4 (Fig. 2). This observation can indicate the preferential formation of one of the two possible diastereoisomers generated by the helical conformations adopted by the ligand around the metal. However, the absence of any meaningful dichroic signal suggests a weak preference over one diastereoisomer.

Dinuclear complexes 1-L-Phe. When water is removed from the solution adding activated molecular sieves, the dimeric dinuclear complex 1-L-Phe is formed in less than two hours (Scheme 1). Compound 1-L-Phe has been isolated as a yellow

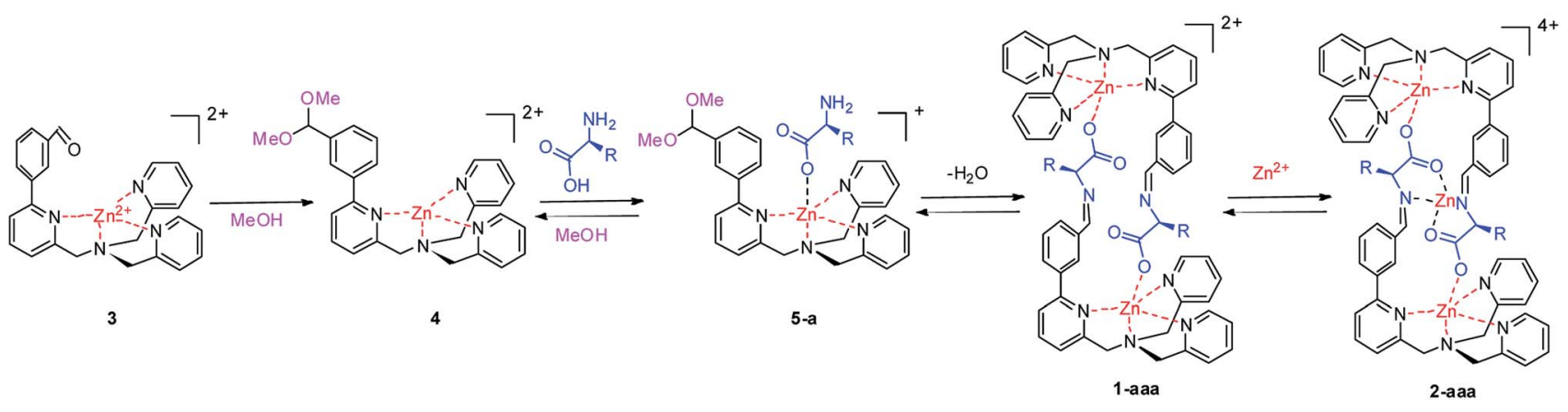

Scheme 1 Complex 3 dissolved in methanol give rise to the formation of acetal 4 within hours depending on the initial amount of water. Addition to this mixture of amino acid L-Phe leads to adduct 5-L-Phe which, in dry conditions, evolves to the dinuclear adduct complex 1-L-Phe or to complex 2-L-Phe in the presence of an excess of $\mathrm{Zn}(॥)$ in solution. The counteranions are perchlorate. 
solid simply by evaporation of the solvent and the ${ }^{1} \mathrm{H}-\mathrm{NMR}$ indicates predominately the presence of one single species. The disappearance of the signal corresponding to the characteristic acetal proton together with the appearance of the imine signal at $7.7 \mathrm{ppm}$ confirmed the condensation (Fig. 2d).

In this compound, the presence of six doublets $(J \sim 16 \mathrm{~Hz})$ between $\delta=3.9$ and $4.6 \mathrm{ppm}$, combined with VT-NMR experiments $^{7 b}$ suggest that the picolyl methylene hydrogens are blocked in a single helical conformation as expressed by the wide separation of the signals. Further confirmation also comes from ESI-MS experiments that show the characteristic isotopic pattern corresponding to the dinuclear zinc complex.

Trinuclear complexes 2-L-Phe. A serendipitous discover has also led to notice, in the dynamic mixture, the formation of a trinuclear complex when an excess of zinc salt is present. The trinuclear complex 2-L-Phe can be either obtained starting from the dinuclear complex 1-L-Phe by addition of half-equivalent of zinc salt or directly from complex 3 . The isolation of the pure compound is possible by crystallization because the tetra positively charged assembly is poorly soluble in methanol. On the other hand, its high solubility in acetonitrile allows acquisition of ${ }^{1} \mathrm{H}-\mathrm{NMR}$ and ESI-MS spectra, the latter showing the characteristic isotopic pattern corresponding to the mono charged species containing three metal centres. The ${ }^{1} \mathrm{H}$ NMR analysis of 2-L-Phe confirms that picolyl methylene hydrogens are blocked in a single helical conformation in a similar fashion as 1-L-Phe (Fig. 2e).

\section{Stereochemical analysis of 1-aaa and 2-aaa assembly formation and self-sorting experiment}

As shown in our previous work, ${ }^{7 a, 7 b}$ when 1-Phe is formed varying amino acid e.e., a linear response of the CD signal is observed. This linearity, besides constituting the bases for a probe, does not give information about the stereochemical recognition process along the formation of a chiral dimeric structure. In other words, two types of structures can be formed starting from a racemic mixture of the amino acid: (i) homochiral, where both the amino acids incorporated in the structure have the same configuration $\left(C_{2}\right.$ symmetry homonarcissistic assembly, CD active) or (ii) heterochiral, where the two amino acids have opposite configuration $\left(S_{2}\right.$ symmetry hetero-narcissistic assembly, CD inactive). ${ }^{9}$ Due to their symmetry these two systems can not be identified using NMR and on the other hand, the linearity in CD response by itself does not give information on which type of structure is preferentially formed. In other word, independently by the assembly mechanism a linear correlation between e.e. and CD response is obtained (for a detailed explanation on how e.e. and CD correlates see $\mathrm{ESI} \dagger$ paragraph 3 ).

In order to investigate which type of assembly was more stable in solution, we devised an experiment where the dinuclear 1 and trinuclear 2 complexes were prepared from a solution containing a solution of $\mathbf{L}$-Val and D-Ala, two pseudoracemic amino acids that have similar side chains.

Using the pseudo-racemic mixture, the dinuclear 1-aaa have been obtained following our standard procedure. The resulting mixture was analysed using ESI-MS experiments to understand the stereochemistry of amino acids incorporation in the selfsorting experiment (Fig. 3a and ESI $\dagger$ Section 4). Assuming a similar response factor for the pseudo-diastereoisomers in the ESI-MS experiment, ${ }^{7,10}$ the dinuclear 1-aaa assembly displays a small tendency to prefer the formation of the heterochiral structure. However, the three pseudo-diastereoisomers 1-D-AlaD-Ala : 1-L-Val-D-Ala + 1-D-Val-L-Ala: 1-L-Val-L-Val are close to the statistical $1: 2: 1$ (measured $1: 4: 2$ ).

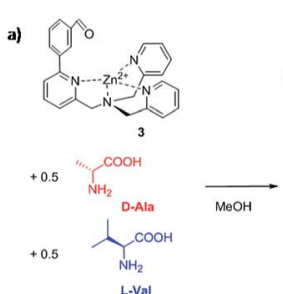

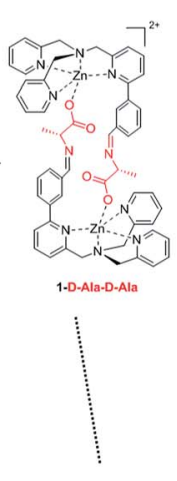
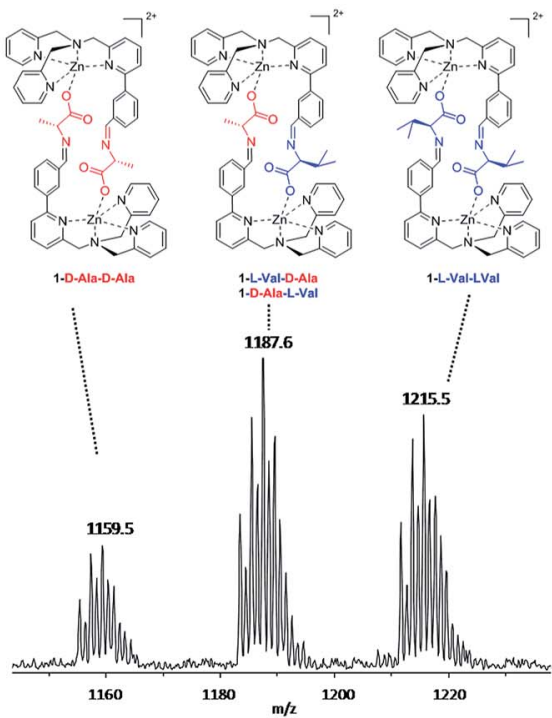
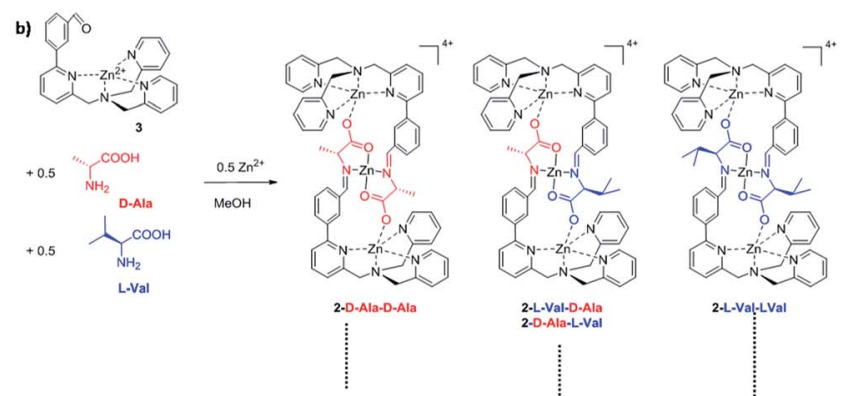

2-L-Val-D-Ala
2-D-Ala-L-Val

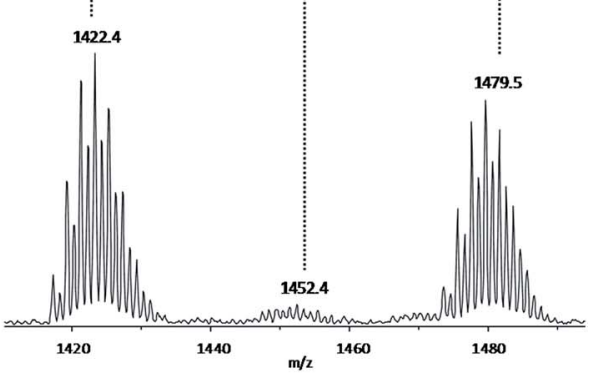

Fig. 3 ESI-MS signals corresponding to (a) 1-D-Ala-D-Ala, 1-L-Val-D-Ala and 1-D-Ala-L-Val, 1-L-Val-L-Val; (b) 2-D-Ala-D-Ala, 2-L-Val-D-Ala and 2D-Ala-L-Val, 2-L-Val-L-Val. The cluster in the ESI-MS spectra are referred to the mono-charged species in which the counteranions are perchlorate. 

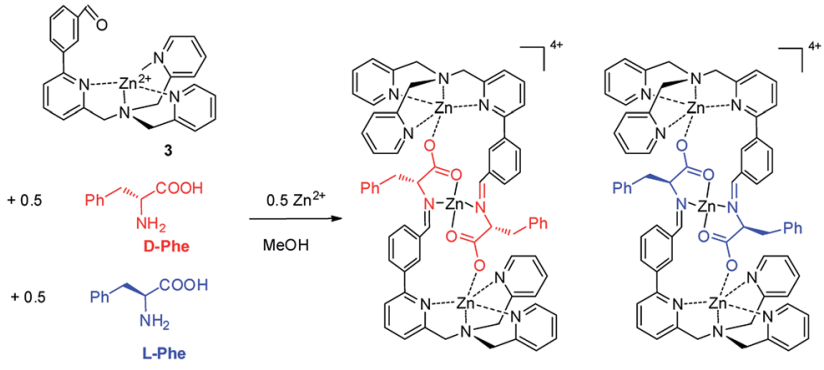

2-D-Phe-D-Phe

2-L-Phe-L-Phe

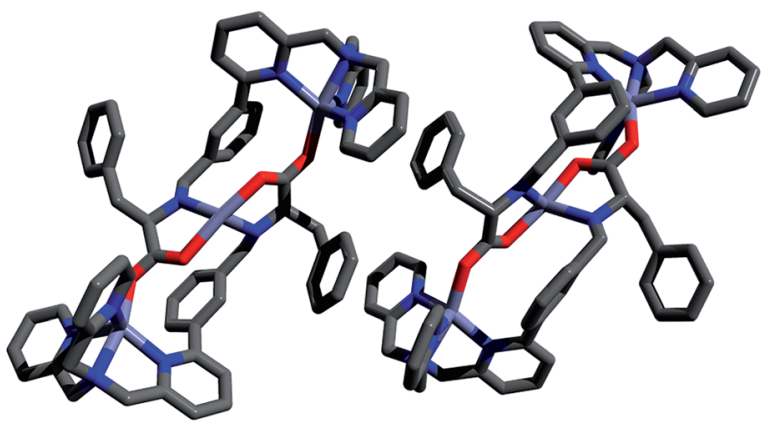

Fig. $4 X$-ray crystal structure of 2-Phe starting from the racemic Phe. Both 2-D-Phe-D-Phe and the 2-L-Phe-L-Phe are present in the same unit cell. The counteranions are perchlorates.

The more stable pseudo-diastereoisomer in solution, in the case of the dinuclear system 1-aaa, has the amino acids with opposite configuration. The same experiment was repeated adding 0.5 equivalents of zinc(II) perchlorate. In this case, we are in the situation were the trinuclear 2-aaa systems is formed. As it can be seen from ESI-MS (Fig. 3b), the 2-aaa shows a complete preference toward the formation of the homochiral assembly 2-D-Ala-D-Ala and the 2-L-Val-L-Val. In other words, the presence of the extra metal centre drives the system toward the formation of the enantio-narcissistic structure. Most probably, the metal adds an extra constriction to the amino acidic cleft which allows only the selection of identical amino acids.

Interestingly, another proof of the enantio narcissistic behaviour of the trinuclear assembly came from the X-ray analysis of crystals grown up when a racemic mixture of $\mathbf{L} / \mathbf{D}^{-}$ Phe was used in the synthesis (Fig. 4). The diffraction revealed a racemate which had in the same unit cell only the two enantiomeric homochiral narcissistic assemblies.

\section{Conclusions}

In this study, we have shown that in our molecular architectures, the combination of coordination chemistry and DCC results in a delicate and intricate system which can be finely biased by external stimuli of the thermodynamic equilibria. In detail, solvent, molecular sieves, excess of components, temperature, and stereochemistry of the components, can have a profound impact in the outcome of a dynamic library. Even at a first sight this seems a very complicated system, the deep knowledge acquired in each step of the process allows to drive the synthesis towards the desired products. In other words, we were able not only to set-up an analytical method for the easy and fast detection of amino acid e.e., but also, through the synthesis and characterization of the pure compounds involved in the dynamic process, to gather information about the metal induced self-sorting of the self-assembly which has revealed the formation of an enantio narcissistic assembly.

\section{Conflicts of interest}

There are no conflicts to declare.

\section{Acknowledgements}

Financial support from the Italian MIUR (PRIN-2010-11 2010CX2TLM_002), from the University of Padova (PRATCPDA153122, Cariparo Dottorati Internazionali NACS). Useful discussions have been carried within the frame of Cost Action CM1304 - Emergence and Evolution of Complex Chemical Systems.

\section{Notes and references}

1 (a) J. Bunzen, J. Iwasa, P. Bonakdarzadeh, E. Numata, K. Rissanen, S. Sato and M. Fujita, Angew. Chem., Int. Ed., 2012, 51, 3161-3163; (b) Y. Inokuma, S. Yoshioka, J. Ariyoshi, T. Arai, Y. Hitora, K. Takada, S. Matsunaga, K. Rissanen and M. Fujita, Nature, 2013, 495, 461-466; (c) D. A. Leigh, R. G. Pritchard and A. J. Stephens, Nat. Chem., 2014, 6, 978-982; (d) V. Marcos, A. J. Stephens, J. JaramilloGarcia, A. L. Nussbaumer, S. L. Woltering, A. Valero, J.-F. Lemonnier, I. J. Vitorica-Yrezabal and D. A. Leigh, Science, 2016, 352, 1555-1559; (e) K. S. Chichak, S. J. Cantrill, A. R. Pease, S.-H. Chiu, G. W. V. Cave, J. L. Atwood and J. F. Stoddart, Science, 2004, 304, 13081312; (f) J.-N. Rebilly, B. Colasson, O. Bistri, D. Over and O. Reinaud, Chem. Soc. Rev., 2015, 44, 467-489; (g) S. H. A. M. Leenders, R. G. Doria, B. de Bruin and J. N. H. Reek, Chem. Soc. Rev., 2015, 44, 433-448; (h) S. Durot, J. Taesch and V. Heitz, Chem. Rev., 2014, 114, 8542-8578; (i) T.-Z. Xie, K. J. Endres, Z. Guo, J. M. Ludlow, C. N. Moorefield, M. J. Saunders, C. Wesdemiotis and G. R. Newkome, J. Am. Chem. Soc., 2016, 138, 12344-12347; (j) J. Atcher, J. Bujons and I. Alfonso, Chem. Commun., 2017, 53, 4274-4277; (k) J. Atcher, A. Moure, J. Bujons and I. Alfonso, Chem.-Eur. J., 2015, 21, 6869-6878; (l) A. M. Valdivielso, F. Puig-Castellví, J. Atcher, J. Solà, R. Tauler and I. Alfonso, Chem.-Eur. J., 2017, 23, 10702; (m) M. Ciaccia, I. Tosi, L. Baldini, R. Cacciapaglia, L. Mandolini, S. Di Stefano and C. A. Hunter, Chem. Sci., 2015, 6, 144-151; (n) L. You, D. Zha and E. V. Anslyn, Chem. Rev., 2015, 115, 7840-7892; (o) D. Zamora-Olivares, T. S. Kaoud, K. N. Dalby and E. V. Anslyn, J. Am. Chem. Soc., 2013, 135, 14814-14820; (p) Z. Kostereli, R. Scopelliti and K. Severin, Chem. Sci., 2014, 5, 2456-2460; (q) T. Takeuchi and S. Matile, Chem. Commun., 2013, 49, 1929; (r) E. Faggi, C. Vicent, S. V. Luis and I. Alfonso, Org. Biomol. Chem., 2015, 13, 11721-11731; $(s)$ E. Faggi, 
A. Moure, M. Bolte, C. Vicent, S. V. Luis and I. Alfonso, J. Org. Chem., 2014, 79, 4590-4601.

2 (a) M. Mastalerz, Angew. Chem., Int. Ed., 2010, 49, 5042-5053; (b) A. Granzhan, C. Schouwey, T. Riis-Johannessen, R. Scopelliti and K. Severin, J. Am. Chem. Soc., 2011, 133, 7106-7115; (c) T. Mitra, K. E. Jelfs, M. Schmidtmann, A. Ahmed, S. Y. Chong, D. J. Adams and A. I. Cooper, Nat. Chem., 2013, 5, 276-281; (d) T. K. Ronson, C. Giri, N. Kodiah Beyeh, A. Minkkinen, F. Topić, J. J. Holstein, K. Rissanen and J. R. Nitschke, Chem.-Eur. J., 2013, 19, 3374-3382; (e) S. Zarra, D. M. Wood, D. A. Roberts and J. R. Nitschke, Chem. Soc. Rev., 2015, 44, 419-432; $(f)$ M. J. Barrell, A. G. Campaña, M. von Delius, E. M. Geertsema and D. A. Leigh, Angew. Chem., Int. Ed., 2011, 50, 285-290.

3 (a) D. Leung, S. O. Kang and E. V. Anslyn, Chem. Soc. Rev., 2012, 41, 448-479; (b) G. Pescitelli, L. Di Bari and N. Berova, Chem. Soc. Rev., 2014, 43, 5211-5233; (c) N. Berova, L. Di Bari and G. Pescitelli, Chem. Soc. Rev., 2007, 36, 914-931; (d) C. Wolf and K. W. Bentley, Chem. Soc. Rev., 2013, 42, 5408-5424.

4 (a) S. Hayashi, M. Yotsukura, M. Noji and T. Takanami, Chem. Commun., 2015, 51, 11068-11071; (b) P. Metola, E. V. Anslyn, T. D. James and S. D. Bull, Chem. Sci., 2012, 3, 156-161; (c) Z. A. De los Santos and C. Wolf, J. Am. Chem. Soc., 2016, 138, 13517-13520; (d) G. Bian, S. Yang, H. Huang, H. Zong, L. Song, H. Fan and X. Sun, Chem. Sci., 2016, 7, 932-938; (e) A. Akdeniz, T. Minami, S. Watanabe, M. Yokoyama, T. Ema and P. Anzenbacher Jr, Chem. Sci., 2016, 7, 2016-2022; (f) Z. A. De los Santos, R. Ding and C. Wolf, Org. Biomol. Chem., 2016, 14, 1934-1939; (g) C. Ni, D. Zha, H. Ye, Y. Hai, Y. Zhou, E. Anslyn and L. You, Angew. Chem., Int. Ed., 2018, 57, 1300-1305.

5 (a) L. You, J. S. Berman and E. V. Anslyn, Nat. Chem., 2011, 3, 943-948; (b) C.-Y. Lin, S. Lim and E. V. Anslyn, J. Am. Chem. Soc., 2016, 138, 8045-8047; (c) L. You, J. S. Berman, A. Lucksanawichien and E. V. Anslyn, J. Am. Chem. Soc., 2012, 134, 7126-7134; (d) L. You, G. Pescitelli, E. V. Anslyn and L. Di Bari, J. Am. Chem. Soc., 2012, 134, 7117-7125; (e) H. H. Jo, X. Gao, L. You, E. V. Anslyn and M. J. Krische, Chem. Sci., 2015, 6, 6747-6753; (f) L. A. Joyce, M. S. Maynor, J. M. Dragna, G. M. da Cruz, V. M. Lynch, J. W. Canary and E. V. Anslyn, J. Am. Chem. Soc., 2011, 133, 13746-13752; (g) J. Zhang, W. Sheng, H. Gholami, T. Nehira and B. Borhan, Chirality, 2017, 1-6; (h) H. Gholami, M. Anyika, J. Zhang, C. Vasileiou and B. Borhan, Chem.-Eur. J., 2016, 22, 9235-9239; (i) M. Tanasova, M. Anyika and B. Borhan, Angew. Chem., Int. Ed., 2015, 54, 4274-4278; (j) M. Anyika, H. Gholami, K. D. Ashtekar, R. Acho and B. Borhan, J. Am. Chem. Soc., 2014, 136, 550-553; ( $k$ ) H. Gholami, J. Zhang, M. Anyika and B. Borhan, Org. Lett., 2017, 19, 1722-1725; (l) D. Zhang, J. R. Cochrane, S. Di Pietro, L. Guy,
H. Gornitzka, J.-P. Dutasta and A. Martinez, Chem.-Eur. J., 2017, 23, 6495-6498; ( $m$ ) D. Zhang, B. Bousquet, J.-C. Mulatier, D. Pitrat, M. Jean, N. Vanthuyne, L. Guy, J.-P. Dutasta and A. Martinez, J. Org. Chem., 2017, 82, 6082-6088; (n) P. Zardi, K. Wurst, G. Licini and C. Zonta, J. Am. Chem. Soc., 2017, 139, 15616-15619.

6 (a) M. Natali, E. Badetti, E. Deponti, M. Gamberoni, F. A. Scaramuzzo, A. Sartorel and C. Zonta, Dalton Trans., 2016, 45, 14764-14773; (b) N. A. Carmo dos Santos, E. Badetti, M. Natali, K. Wurst, G. Licini and C. Zonta, Dalton Trans., 2017, 46, 16455-16464; (c) N. A. Carmo dos Santos, F. Lorandi, E. Badetti, K. Wurst, A. A. Isse, A. Gennaro, G. Licini and C. Zonta, Polymer, 2017, 128, 169-176.

7 (a) F. A. Scaramuzzo, G. Licini and C. Zonta, Chem.-Eur. J., 2013, 19, 16809-16813; (b) E. Badetti, K. Wurst, G. Licini and C. Zonta, Chem.-Eur. J., 2016, 22, 6515-6518; (c) R. Berardozzi, E. Badetti, N. A. Carmo dos Santos, K. Wurst, G. Licini, G. Pescitelli, C. Zonta and L. Di Bari, Chem. Commun., 2016, 52, 8428-8431; (d) F. A. Scaramuzzo, E. Badetti, G. Licini and C. Zonta, Eur. J. Org. Chem., 2017, 11, 1438-1442; (e) C. Bravin, E. Badetti, F. A. Scaramuzzo, G. Licini and C. Zonta, J. Am. Chem. Soc., 2017, 139, 64566460; $(f)$ N. A. Carmo dos Santos, E. Badetti, G. Licini, S. Abbate, G. Longhi and C. Zonta, Chirality, 2018, 30, 6573; $(g)$ C. Bravin, E. Badetti, R. Puttreddy, F. Pan, K. Rissanen, G. Licini and C. Zonta, Chem.-Eur. J., 2018, 24, 2936-2943.

8 For other systems for e.e. detection of amino-acids see: $(a)$ F. Biedermann and W. M. Nau, Angew. Chem., Int. Ed., 2014, 53, 5694-5699; (b) E. G. Shcherbakova, V. Brega, T. Minami, S. Sheykhi, T. D. James and P. Anzenbacher Jr, Chem.-Eur. J., 2016, 22, 10074-10080; (c) S. Shinoda, K. Terada and H. Tsukube, Chem.-Asian J., 2012, 7, 400405; (d) K. W. Bentley, Y. G. Nam, J. M. Murphy and C. Wolf, J. Am. Chem. Soc., 2013, 135, 18052-18055; (e) N. Kameta, M. Masuda and T. Shimizu, Chem. Commun., 2015, 51, 11104-11107; (f) K. W. Bentley, P. Zhang and C. Wolf, Sci. Adv., 2016, 2, e1501162; (g) K. W. Bentley and C. Wolf, J. Org. Chem., 2014, 79, 6517-6531.

9 (a) A. Wu and L. Isaacs, J. Am. Chem. Soc., 2003, 125, 48314835; (b) M. L. Saha and M. Schmittel, Org. Biomol. Chem., 2012, 10, 4651-4684.

10 Due to a similar structure and charge of the measured peak we assume a similar response factor for the assemblies. (a) S. P. Black, D. M. Wood, F. B. Schwarz, T. K. Ronson, J. J. Holstein, A. R. Stefankiewicz, C. A. Schalley, J. K. M. Sanders and J. R. Nitschke, Chem. Sci., 2016, 7, 2614-2620; (b) E. Leize, A. Jaffrezic and A. Van Dorsselaer, J. Mass Spectrom., 1996, 31, 537-544; (c) P. N. W. Baxter, R. G. Khoury, J.-M. Lehn, G. Baum and D. Fenske, Chem. Eur. J., 2000, 6, 4140-4148. 